\title{
Cytogenetic evidences on the evolutionary relationships between the tetraploids of the section Rhizomatosae and related diploid species (Arachis, Leguminosae)
}

\author{
Alejandra Marcela Ortiz ${ }^{1,2}$ - Germán Robledo ${ }^{1,2}$ - Guillermo Seijo ${ }^{1,2}$ • \\ José Francisco Montenegro Valls ${ }^{3}$ - Graciela Inés Lavia ${ }^{1,2}$
}

Received: 26 January 2017 / Accepted: 22 March 2017

(C) The Botanical Society of Japan and Springer Japan 2017

\begin{abstract}
Rhizomatosae is a taxonomic section of the South American genus Arachis, whose diagnostic character is the presence of rhizomes in all its species. This section is of particular evolutionary interest because it has three polyploid (A. pseudovillosa, A. nitida and A. glabrata, $2 \mathrm{n}=4 x=40$ ) and only one diploid (A. burkartii, $2 \mathrm{n}=2 x=20$ ) species. The phylogenetic relationships of these species as well as the polyploidy nature and the origin of the tetraploids are still controversial. The present study provides an exhaustive analysis of the karyotypes of all rhizomatous species and six closely related diploid species of the sections Erectoides and Procumbentes by cytogenetic mapping of DAPI/CMA heterochromatin bands and 5S and 18-26S rDNA loci. Chromosome banding showed variation in the DAPI heterochromatin distribution pattern, which, together with the number and distribution of rDNA loci, allowed the characterization of all species studied here. The bulk of chromosomal markers suggest that the three rhizomatous tetraploid species constitute a natural group and may have at least one common diploid ancestor. The cytogenetic data of the diploid species analyzed evidenced that the only rhizomatous diploid species-A. burkartii-has a karyotype pattern different from those of the rhizomatous tetraploids, showing that it
\end{abstract}

Alejandra Marcela Ortiz

aortiz@agr.unne.edu.ar; ortizalejandr@gmail.com

1 Instituto de Botánica del Nordeste (CONICETUNNE), CC 209, Sargento Juan Bautista Cabral 2131, 3402BKG Corrientes, Argentina

2 Facultad de Ciencias Exactas y Naturales y Agrimensura (UNNE), Av. Libertad 5000, 3402BKG Corrientes, Argentina

3 Embrapa Recursos Genéticos e Biotecnologia, Caixa Postal 02372, 70770-917 Brasília, Distrito Federal, Brazil is not likely the genome donor of the tetraploids and the non-monophyletic nature of the section Rhizomatosae. Thus, the tetraploid species should be excluded from the $\mathrm{R}$ genome, which should remain exclusively for A. burkartii. Instead, the karyotype features of these tetraploids are compatible with those of different species of the sections Erectoides and Procumbentes (E genome species), suggesting the hypothesis of multiple origins of these tetraploids. In addition, the polyploid nature and the group of diploid species closer to the tetraploids are discussed.

Keywords Arachis - Evolutionary relationships ·

Karyotype $\cdot$ Heterochromatin $\cdot$ rDNA loci $\cdot$ Rhizomatosae

\section{Introduction}

The genus Arachis (Leguminosae) is native to South America and comprises 81 formally recognized species (Krapovickas and Gregory 1994; Santana and Valls 2015; Valls and Simpson 2005; Valls et al. 2013). These species are mostly autogamous, with geocarpic fruits, and have two basic chromosome numbers, $x=9$ and $x=10$ (Fernández and Krapovickas 1994; Krapovickas and Gregory 1994; Lavia et al. 2008; Peñaloza and Valls 2005). These entities have been assembled into nine taxonomic sections: Arachis, Caulorrhizae, Erectoides, Extranervosae, Heteranthae, Procumbentes, Rhizomatosae, Trierectoides, and Triseminatae (Krapovickas and Gregory 1994; Santana and Valls 2015; Valls and Simpson 2005; Valls et al. 2013).

According to cross compatibility assays and detailed cytogenetic analyses, the section Arachis has six different genomes (A, B, D, F, G and K) (Smartt et al. 1978; Stalker 1991; Robledo and Seijo 2008, 2010; Robledo et al. 2009; Silvestri et al. 2015). The other species of the genus are still 
assigned to other six genomes based on the infrageneric division (Smartt and Stalker 1982): Am (Heteranthae), C (Caulorrhizae), E (Trierectoides, Erectoides and Procumbentes), Ex (Extranervosae), T (Triseminatae) and R (Rhizomatosae). However, a better characterization of these genomes and the species within them is needed.

The section Rhizomatosae is currently defined based exclusively on morphological features, mainly by the presence of rhizomes (Krapovickas and Gregory 1994; Valls and Simpson 2005). This section is a very interesting group, because it is represented by three polyploid (A. pseudovillosa, A. nitida and A. glabrata, $2 \mathrm{n}=4 x=40$ ) and only one diploid (A. burkartii, $2 \mathrm{n}=2 x=20$ ) species (Gregory et al. 1973; Fernández and Krapovickas 1994; Peñaloza and Valls 2005). On the basis of leaf morphology and geographic distribution, two varieties of A. glabrata, var. glabrata and var. hagenbeckii, have been recognized (Krapovickas and Gregory 1994). This species, commonly known as "rhizoma peanut", is the most agronomically important Rhizomatosae species because it produces highquality forage and is used as cover crop and ornamental turf (Prine 1964, 1972; Rouse et al. 2004). Several cultivars, like 'Florigraze', 'Arb', 'Arbrook' and 'Latitude 34' in the USA (Muir et al. 2010; Prine et al. 1981, 1986) and, 'Prine' in Australia (Bowman et al. 1998) have been developed and are commercialized as forage.

From a cytogenetic point of view, the polyploid nature of the rhizomatous tetraploid species has been a controversial issue; while some authors have proposed that $A$. glabrata is autopolyploid (Singh and Simpson 1994), others have suggested that it may be allopolyploid (Gregory and Gregory 1979; Jahnavi and Murty 1985; Raman 1981). More recently, chromosome associations in meiosis of $A$. glabrata and A. nitida (Ortiz et al. 2011) have shown a high degree of homology among the four chromosome sets of the former but partial homology among those of the latter. On this basis, it has been suggested that these species might be autotetraploids or segmental allotetraploids with different degrees of diploidization.

Under the hypothesis of monophyly of the section Rhizomatosae, A. burkartii might be at least one of the parental species of the rhizomatous polyploids. However, several molecular analyses have shown that A. burkartii and the tetraploids are not closely related species (Angelici et al. 2008; Bechara et al. 2010; Friend et al. 2010; Gimenes et al. 2002). Crosses involving the tetraploids of the section Rhizomatosae do not produce $\mathrm{F}_{1}$ hybrids with the diploid A. burkartii (Krapovickas and Gregory 1994), but produce $\mathrm{F}_{1}$ hybrids with diploid species of other sections such as Erectoides (A. hermannii, A. paraguariensis, A. major and A. benthamii), Procumbentes (A. appressipila and A. rigonii) and Arachis (A. batizocoi, A. duranensis and A. stenosperma). Moreover, the tetraploid species are distributed from the Mato Grosso state in Brazil to the north of Argentina, while the diploid A. burkartii grows from the north of Argentina to the north of Uruguay and the south of Brazil (Krapovickas and Gregory 1994; Valls and Simpson 2005), having a narrow contact area in the northeast of Argentina. All this information has raised doubts about the role of $A$. burkartii in the origin of the rhizomatous tetraploids and suggests multiple origins of the tetraploids, including genome donors from different taxonomic sections.

Karyotype characterizations have played an important role in the understanding of the genomic affinities within the genus Arachis (Seijo et al. 2017). The analysis of the complements by banding techniques and by mapping rDNA loci by fluorescent in situ hybridization (FISH) has provided useful information to characterize the six genomes (A, B, D, F, G and K) of the section Arachis (Robledo and Seijo 2008, 2010; Robledo et al. 2009, 2010; Silvestri et al. 2015), to identify the most probable diploid progenitors of A. hypogaea (Seijo et al. 2004), and to demonstrate the autopolyploid ( $3 x$ ) origin of the tropical forage A. pintoi (Lavia et al. 2011). In addition, the analysis of chromosome homeologies has allowed suggesting evolutionary relationships among species of the section Arachis.

In this context, we conducted a detailed cytogenetic study by analyzing the distribution patterns of heterochromatin and rDNA loci localization in all the rhizomatous species and six diploid species of the sections Erectoides and Procumbentes, in order to: (1) describe chromosomal markers that may contribute to the genome characterization of the species of the section Rhizomatosae, (2) cast light on the evolutionary relationships among the species of the section Rhizomatosae and (3) infer the nature of the three tetraploid species and their probable diploid genome donors. The data obtained are discussed considering the karyotype information available for other Arachis species.

\section{Materials and methods}

\section{Plant material}

The provenances and the collection numbers of the species analyzed are cited in Table 1 . Seeds and rhizomes for this study were obtained from the Instituto Nacional de Tecnología Agropecuaria-Manfredi (Córdoba, Argentina), the Instituto de Botánica del Nordeste (Corrientes, Argentina), and the Centro Nacional de Recursos Genéticos e Biotecnologia (Embrapa Cenargen, Brasilia, Brazil). The diploid species analyzed here were selected among those reported to produce hybrids with the rhizomatous tetraploids (Stalker 1985; Krapovickas and Gregory 1994). The geographic distribution of each of the species analyzed is shown in Fig. 1. 
Table 1 List of the Arachis species studied, including their provenance and collection number

Section and species $\quad$ Provenance $^{\mathrm{a}}$ and collection number ${ }^{\mathrm{b}}$

Sect. Rhizomatosae Krapov. and W.C. Greg.

A. burkartii Handro

A. glabrata Benth var. glabrata

A. glabrata Benth. var. hagenbeckii (Harms ex Kuntze) F. J. Herm.

A. nitida Valls, Krapov. and C.E. Simpson

A. pseudovillosa (Chodat and Hassl.) Krapov. and W.C. Greg.

Sect. Erectoides Krapov. and W.C. Greg.

A. hermannii Krapov. and W.C. Greg.

A. major Krapov. and W. C. Greg.

A. paraguariensis Chodat and Hassl. subsp. Paraguariensis

A. paraguariensis subsp. capibariensis Krapov. and W.C. Greg.

Sect. Procumbentes Krapov. and W.C. Greg

A. appressipila Krapov. and W.C. Greg.

A. lignosa (Chodat and Hassl.) Krapov. and W.C. Greg.

A. rigonii Krapov. and W.C. Greg.
Argentina, Prov. Misiones, Dept. Apóstoles, Azara, 2805'26.6" S, $55^{\circ} 41^{\prime 2} 25.4^{\prime \prime}$ W. Se., La., So. 2839

Argentina, Prov. Corrientes, Dept. Mercedes, PR 123, km 155.5. Se., So. 2865

Argentina, Prov. Corrientes, Dept. Monte Caseros, 30¹1'31.5" S, $57^{\circ} 41^{\prime} 47^{\prime \prime}$ W. Se., So. 2872

Argentina, Prov. Corrientes. Dept. Ituzaingó, PR 34 to San Carlos, 27³1'11.4" S, 5604'09" W. La., Or., Cll., Vg. 121

Argentina, Prov. Corrientes, Dept. Concepción, NR 117, km 28. Se., So. 2876

Argentina, Prov. Misiones, Dept. Candelaria, road to Profundidad, $5 \mathrm{~km}$ SW from NR 12. Se., La., So. 2842

Paraguay, Dept. Paraguari, 2 km N from Caapucú. K., G., P., Sc. 30107

Paraguay, Dept. Amambay, 21 km W from Bella Vista. Sv., Pz., Hn. 3785

Paraguay, Dept. Amambay, Finca Elvira, 20 km NW from Pedro Juan Caballero. G., K. 10559

Brazil, St. MS, Mun. Coxim, $1.5 \mathrm{~km} \mathrm{~W}$ from BR-163, $18^{\circ} 32^{\prime} \mathrm{S}, 54^{\circ} 45^{\prime} \mathrm{W}$. V., R., Ge., Sv. 7560

Brazil, St. MS, Mun. Rio Negro, 19²4'09" S, 55²1'29" W. V., Po., Bi. 9468

Brazil, St. MS, Mun. Aquidauana, BR-262, 20²0’ S, 56 $06^{\prime}$ W. V., R., Ge., Sv. 7632

Paraguay, Dept. Cordillera, $1 \mathrm{~km} \mathrm{~N}$ from NR 2, road Ipacarai to San Bernardino. K., G., P. 30109

Brazil, St. MS, Mun. Porto Murtinho, road to Jardim. H., L., K., He. 565/566

Brazil, St. MS, Corumbá. G., K., P. 9993

Brazil, St. MS, Porto Murtinho. V., Rc., Sg., Sv. 13,570

Bolivia, Dept. Santa Cruz, Santa Cruz de las Sierra. G., K., P. 10034

${ }^{a} N R$ National route, $P R$ Provincial route, BR Brazilian route, Prov province, St State, Dept department, Mun Municipality

${ }^{\mathrm{b}}$ Collectors: Bi, L. Bianchetti; Cll, M. Collavino; G, W.C. Gregory; Ge, M.A.N. Gerin; H, R.O. Hammons; He, V. Hemsy; Hn, R. Heyn; K, A. Krapovickas; L, W.R. Langford; La, G.I. Lavia; Or, A.M. Ortiz; P, J.R. Pietrarelli; Po, A. Pott; Pz, E. Pizarro, R, V.R. Rao; Rc, R.C. Oliveira; Sc, A. Schinini; Se, J.G. Seijo; Sg, A.K. Singh; So, V. Solís Neffa; Sv, G.P. Silva; V, J.F.M. Valls; Vg, A. Vega

\section{Chromosome preparations}

All plants were grown under greenhouse conditions. Healthy root tips (5-20 mm long) of seedlings and rhizomes were pretreated with $2 \mathrm{mM}$ 8-hydroxyquinoline for $3 \mathrm{~h}$ at room temperature (Fernández and Krapovickas 1994) and fixed and stored in absolute ethanol:glacial acetic acid (3:1) at $-20^{\circ} \mathrm{C}$. Root apices were digested in $1 \%(w / v)$ cellulose (from Trichoderma viride; Onozuka R-10, Serva) plus $10 \%(\mathrm{v} / \mathrm{v})$ pectinase dissolved in $40 \%$ glycerol (from Aspergillus niger, Sigma-Aldrich) in $0.01 \mathrm{M}$ citrate buffer, $\mathrm{pH} 4.8$, at $37^{\circ} \mathrm{C}$ for $60 \mathrm{~min}$. Subsequently, the meristematic cells were removed from the root tip and squashed in $45 \%$ $(\mathrm{v} / \mathrm{v})$ aqueous acetic acid. Coverslips were removed with
$\mathrm{CO}_{2}$ and the slides were air dried, aged for 1-2 days at room temperature, and then kept at $-20^{\circ} \mathrm{C}$ until use.

\section{CMA/DAPI staining}

Double staining with the fluorochromes chromomycin A3 (CMA, Sigma Aldrich) and diamino-2-phenyl-indole (DAPI, Sigma Aldrich) was performed to reveal GC-rich and AT-rich heterochromatic regions respectively, according to Schweizer (1976) with minor modifications. The aged slides were double-stained at room temperature with $0.5 \mathrm{mg} / \mathrm{mL}$ of CMA for $60 \mathrm{~min}$ and subsequently with $2 \mu \mathrm{g} /$ $\mu \mathrm{L}$ of DAPI for $30 \mathrm{~min}$. After that, the slides were mounted with Vectashield medium (Vector Laboratories). 


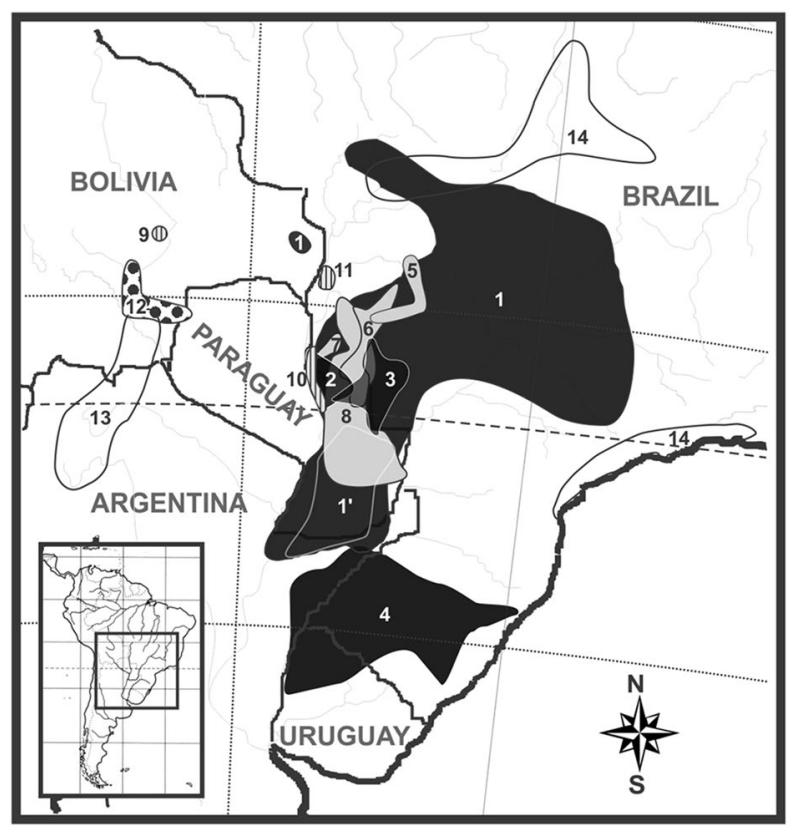

Fig. 1 Geographic distribution of the Arachis species studied. 1 A. glabrata var. glabrata, I' A. glabrata var. hagenbeckii, 2 A. nitida, 3 A. pseudovillosa, 4 A. burkartii, 5 A. hermannii, 6 A. major, 7 A. paraguariensis subsp. capibariensis, 8 A. paraguariensis subsp. paraguariensis, 9 A. rigonii, 10 A. lignosa, 11 A. appressipila, 12 A. batizocoi, 13 A. duranensis, 14 A. stenosperma. Only the distribution of the species of each section analyzed here are represented in the map: black shaded: Rhizomatosae species, gray shaded: Erectoides species, striped: Procumbentes species, dotted: K genome species, and black solid line: A genome species

\section{Probe labeling and fluorescent in situ hybridization}

The 5S rDNA and 18S-26S rDNA loci were simultaneously localized using the probes pA5S, pA18S and pA26S isolated from genomic DNA of A. hypogaea (Robledo and Seijo 2008) and labeled by nick translation with digoxigenin-11-dUTP (Roche) or biotin-11-dUTP (Sigma Aldrich). Pretreatment of slides, chromosome and probe denaturation, conditions for the in situ hybridization (hybridization mixes containing DNA probes at a concentration of $2.5-3.5 \mathrm{ng} / \mu \mathrm{L}$, with a stringency to allow sequences with $80-85 \%$ identity to remain hybridized), post-hybridization washing, blocking and indirect detection with fluorochrome-conjugated antibodies were performed according to Moscone et al. (1996). The first set of antibodies consisted of anti-biotin produced in goat and monoclonal anti-digoxigenin conjugated to fluorescein isothiocyanate (FITC) produced in mouse, and the second set consisted of anti-goat conjugated to tetramethyl-rhodamine isothiocyanate (TRITC) produced in rabbit and antimouse conjugated to FITC produced in sheep (all from Sigma-Aldrich). Preparations were counterstained and mounted with Vectashield medium containing $2 \mathrm{mg} / \mathrm{mL}$ of
DAPI. Counterstaining with DAPI revealed a C-bandinglike pattern, with major heterochromatic bands fluorescing more intensively (cf. Seijo et al. 2004).

\section{Image capturing and chromosome analysis}

Red, green, yellow and blue images were captured in black and white using appropriate filters for TRITC, FITC, CMA, and DAPI excitation, respectively. Digital images were combined and processed using Photoshop software, version 12.0 (Adobe), only with functions that applied equally to the whole image.

Chromosome measurements were carried out after FISH treatment on at least eight metaphases from different individuals using the free version of the MicroMeasure 3.3 program (Reeves 2001). The centromeric index ( $\mathrm{ci}=$ short arm length $\times 100 /$ chromosome length) was used to classify the chromosomes as metacentric $(m, \mathrm{ci}=50-37.51)$ or submetacentric ( $\mathrm{sm}, \mathrm{ci}=37.50-25.01)$, according to Levan et al. (1964). Satellite (SAT) chromosomes were classified according to Fernández and Krapovickas (1994) and Lavia (2000). Chromosome bands and rDNA loci were mapped using the index $d i=d x \quad 100 / a$, where $d=$ distance of loci center from the centromere and $a=$ length of the corresponding chromosome arm, according to Greilhuber and Speta (1976).

Data from homologous chromosomes (determined by length, centromeric index, and patterns of bands and rDNA loci) were combined to obtain mean values, first between chromosomes in the same metaphase and subsequently among different metaphases of the same species. The intrachromosomal and interchromosomal asymmetry indices were determined using the $A_{1}$ and $A_{2}$ indices respectively (Romero-Zarco 1986). Mean karyotype values for each species were represented as haploid complements in the idiograms. Chromosomes were ordered primarily by morphology and then by decreasing length. Some chromosomes within each idiogram were re-ordered according to tentative homeologies on the basis of the current nomenclature proposed for other Arachis species (Robledo et al. 2009; Robledo and Seijo 2010; Seijo et al. 2004). In the tetraploid species, the tentative homeologous/homologous chromosomes were identified with the same number.

A cluster analysis of the chromosome data was carried out to examine the karyotype similarity among the rhizomatous tetraploids and the diploid species of the sections Rhizomatosae, Erectoides, Procumbentes and Arachis. Additional data for three species of the section Arachis, A. batizocoi, A. duranensis and A. stenosperma, were extracted from Robledo et al. (2009) and Robledo and Seijo (2010). A matrix of 15 operational taxonomic units (OTUs) $\times 18$ chromosome variables was constructed. The chromosome variables considered were: the mean chromosome 
length (ML), centromeric index (CI), intrachromosomal asymmetry index $\left(\mathrm{A}_{1}\right)$, interchromosomal asymmetry index $\left(\mathrm{A}_{2}\right)$, percentage of $m$ and $s m$ chromosomes, type of SAT chromosomes, percentage of centromeric $\mathrm{DAPI}^{+}$heterochromatin per complement, percentage of chromosomes with centromeric DAPI ${ }^{+}$heterochromatic bands, percentage of chromosomes with subtelomeric $\mathrm{DAPI}^{+}$heterochromatic bands, pattern of DAPI band distribution (absent, conspicuous and dot-like bands), percentage of chromosomes carrying the 5S and 18-26S rDNA loci, position (interstitial vs. proximal) of the 5S rDNA locus on pair \#3 and the 18-26S rDNA locus located on the SAT chromosomes, co-localization of the 18-26S and 5S rDNA loci on the same chromosome pair (presence vs. absence) as well as the presence of two 18-26S rDNA loci on the SAT chromosomes and the presence of the A9 chromosomes (the characteristic small pair of the A genome). The InfoStat program version 2015 (Di Rienzo et al. 2015) was used to standardize the matrix, to calculate the average taxonomic distance, and to generate a phenogram. Clustering was performed using the unweighted pair-group method (UPGMA). Phenogram distortion was measured by computing the cophenetic correlation coefficient $(r)$.

\section{Results}

The general karyotype features, the number of heterochromatic bands and the number of the $5 \mathrm{~S}$ and $18 \mathrm{~S}-26 \mathrm{~S}$ sites detected for ten Arachis species are listed in Table 2. Representative somatic metaphases for each species are shown in Figs. 2 and 3 and the consensus idiograms are illustrated in Fig. 4. The interspecific relationships inferred from their karyotypes are shown in Fig. 5.

\section{General karyotype features}

The three tetraploid species of the section Rhizomatosae had their complements mainly constituted by metacentric (m) chromosomes of similar size. Among them, A. pseudovillosa had a haploid karyotype formula composed of $20 \mathrm{~m}$, whereas $A$. nitida and both varieties of A. glabrata had $19 m+1 \mathrm{sm}$. The mean chromosome length ranged from $2.59 \mu \mathrm{m}$ (A. nitida) to $3.19 \mu \mathrm{m}$ (A. pseudovillosa), and the total haploid karyotype length ranged from 51.67 to $63.91 \mu \mathrm{m}$ in the same species. The $\mathrm{A}_{1}$ index ranged from 0.12 (A. pseudovillosa) to 0.17 (A. nitida), while $\mathrm{A}_{2}$ index ranged from 0.11 (both varieties of A. glabrata and A. pseudovillosa) to 0.13 (A. nitida). As a whole, the karyotype of A. pseudovillosa was the most symmetric among the rhizomatous tetraploid species. One pair of SAT chromosomes type 3 A was detected in all tetraploids and corresponded to two of the four metacentric chromosomes \#10.
Arachis burkartii had a haploid karyotype formula composed of $10 \mathrm{~m}$, with a mean chromosome length of $2.96 \mu \mathrm{m}$ and a total haploid karyotype length of $29.62 \mu \mathrm{m}$. The $A_{1}$ and $\mathrm{A}_{2}$ asymmetry indices were 0.17 and 0.15 , respectively. The SAT chromosomes were type 8 and corresponded to the metacentric pair \#10.

The diploid species of the sections Erectoides and Procumbentes had karyotypes composed of chromosomes with similar size and the formulae were $8 m+2$ $s m$ or $9 m+1 s m$. The mean chromosome length ranged from $2.80 \mu \mathrm{m}$ (A. paraguariensis subsp. paraguariensis) to $4.09 \mu \mathrm{m}$ (A. major), and the total haploid karyotype length ranged from $28.05 \mu \mathrm{m}$ to $40.94 \mu \mathrm{m}$ in the same species. The $\mathrm{A}_{1}$ index ranged from 0.15 (A. rigonii) to 0.24 (A. appressipila), while the $\mathrm{A}_{2}$ index ranged from 0.08 (A. paraguariensis subsp. capibariensis) to 0.14 (A. major). All diploid species had one pair of SAT chromosomes (pair \#10), which was submetacentric and type 9 in all species of the section Procumbentes, but metacentric and with different morphology in the section Erectoides (Table 2).

\section{Heterochromatin distribution}

In all the species analyzed, the DAPI direct staining showed a pattern of heterochromatin similar to that detected after FISH. Two different patterns of $\mathrm{DAPI}^{+}$heterochromatin were observed among Rhizomatosae species with different ploidy levels. The karyotypes of the tetraploids had small dot-like $\mathrm{DAPI}^{+} / \mathrm{CMA}^{-}$bands (AT-rich heterochromatin) in the centromeres of all the chromosomes (Fig. 2). These heterochromatic bands were of similar size and the total amount of heterochromatin ranged from 8.07\% (A. glabrata var. hagenbeckii) to $12.10 \%$ (A. pseudovillosa) of the karyotype length (Table 2 ). The karyotype of A. burkartii was completely devoid of detectable heterochromatin (Fig. 2).

Diploid Erectoides and Procumbentes species showed centromeric dot-like $\mathrm{DAPI}^{+} / \mathrm{CMA}^{-}$bands of similar size in all or almost all the chromosomes of the complement (Figs. 3, 4). The total amount of heterochromatin ranged from $7.12 \%$ (A. major) to $12.85 \%$ (A. rigonii) of the karyotype length (Table 2), and in general the species of Erectoides had the lowest amounts of heterochromatin. The heterochromatin was restricted to the centromeres in all the species except in A. rigonii (Fig. 3k) and A. appressipila (Fig. $3 \mathrm{~m}$ ) of the section Procumbentes, which presented one pair of small subtelomeric $\mathrm{DAPI}^{+} / \mathrm{CMA}^{-}$bands on the short arms of metacentric pair \#7.

All rhizomatous tetraploid species had one proximal $\mathrm{CMA}^{+} / \mathrm{DAPI}^{-}$band (GC-rich heterochromatin) on the four chromosomes \#10 (Fig. 2). Arachis nitida had an additional proximal $\mathrm{CMA}^{+} / \mathrm{DAPI}^{-}$band on two chromosomes \#2 (Fig. 2e). In all cases, the $\mathrm{CMA}^{+} / \mathrm{DAPI}^{-}$bands on chromosomes \#10 were localized in the secondary constrictions. 


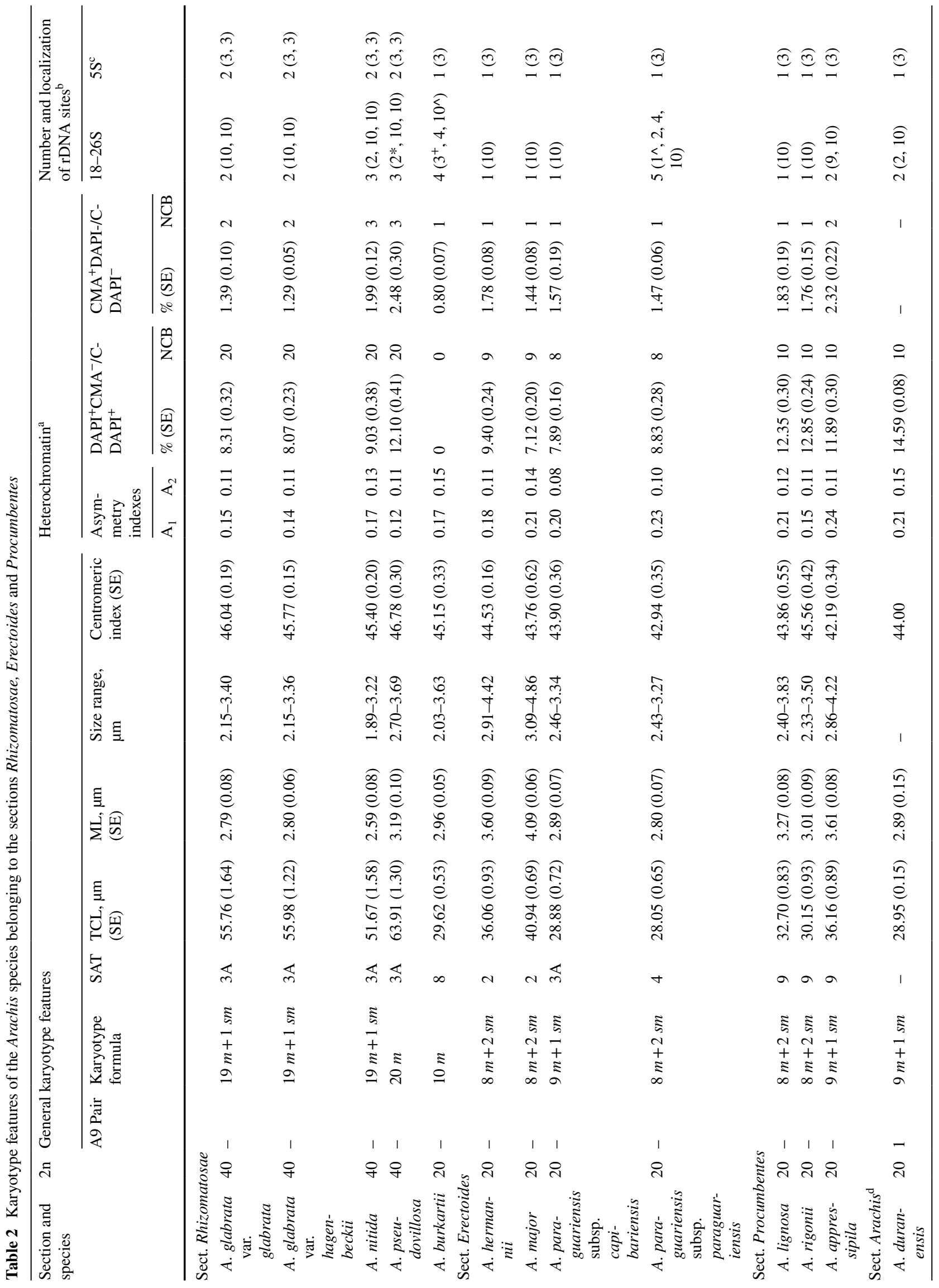


All the diploid species analyzed had $\mathrm{CMA}^{+} / \mathrm{DAPI}^{-}$bands on the proximal (sect. Erectoides) or interstitial secondary constrictions of the short (sect. Procumbentes) and long arms (sect. Rhizomatosae) of pair \#10 (Figs. 2, 3, 4). Additionally, A. appressipila also displayed interstitial $\mathrm{CMA}^{+} /$ DAPI $^{-}$bands on the short arms of submetacentric pair \#9 (Fig. 3m).

\section{Chromosomal mapping of rDNA loci by FISH}

The number of 5S rDNA sites per haploid complement in the Rhizomatosae species was conserved: two pairs were observed in the tetraploids and one pair in the diploid species (Table 2). However, in the tetraploids, the sites were proximally localized on the long arms of pair \#3 (Figs. 2, 4), while in A. burkartii the sites were interstitial (Fig. 2h).

In contrast to the conserved $5 \mathrm{~S}$ rDNA sites, the number and localization of the 18-26S rDNA sites were more variable. Among the Rhizomatosae species, all the tetraploids had one 18-26S rDNA site proximally localized on the four chromosomes \#10 (Figs. 2, 4). Arachis nitida had additional 18-26S rDNA sites on the short arms of two (out of four) chromosomes \#2 (Fig. 2f), while A. pseudovillosa in only one (out of four) chromosome \#2 (Fig. 2d). Arachis burkartii displayed four pairs of 18-26S rDNA sites: the largest and brightest ones were interstitially localized in the secondary constriction of pair \#10, while the other three were detected in the proximal regions of the short arms of pairs \#3 and \#4 and in the long arms of pair \#10 (Figs. 2h, 4).

All the species of the sections Erectoides and Procumbentes had one pair of 18-26S rDNA sites localized in the secondary constrictions of pair \#10 (Figs. 3, 4). Arachis paraguariensis subsp. paraguariensis displayed four additional pairs of 18-26S rDNA sites: two of them proximally localized on both arms of pair \#1, one on the short arms of pair \#2, and the other one interstitially localized on the long arms of pair \#4 (Figs. 2h, 4). Arachis appressipila also had one pair of interstitial sites on the short arms of pair \#9 (Figs. 2n, 4).

All 18-26S rDNA sites co-localized with $\mathrm{CMA}^{+} /$ DAPI $^{-}$bands, except the heteromorphic 18-26S rDNA locus localized on one chromosome \#2 of A. pseudovillosa (Fig. 2c, d), and the sites of pairs \#3, \#4, and \#10 (the proximal ones) in A. burkartii (Fig. $2 \mathrm{~g}, \mathrm{~h}$ ) and pairs \#1, \#2, \#3 in A. paraguariensis subsp. paraguariensis (Fig. 3g, h).

\section{Karyotype similarities}

For the hierarchical cluster analysis using 18 chromosome features, the karyotype data of three species of the section Arachis were included (Fig. 5). Arachis batizocoi (genome 
Fig. 2 Somatic metaphases of Arachis species belonging to section Rhizomatosae after DAPI/CMA double staining (left) and double FISH (right). Yellow signals correspond to the $\mathrm{CMA}^{+} \mathrm{DAPI}^{-} / \mathrm{C}-\mathrm{DAPI}^{-}$heterochromatin bands, gray signals to the $\mathrm{DAPI}^{+} \mathrm{CMA}^{-} / \mathrm{C}-\mathrm{DAPI}^{+}$heterochromatin bands, green signals to the 5S rDNA sites, and red signals to the 18-26S rDNA sites. The asterisk indicates the extra 18S-26S rDNA locus detected on one chromosome \# 2 of A. pseudovillosa. a, b A. glabrata, c, d A. pseudovillosa, $\mathbf{e}, \mathbf{f} A$. nitida, $\mathbf{g}, \mathbf{h}$ A. burkartii. Scale bar $3 \mu \mathrm{m}$

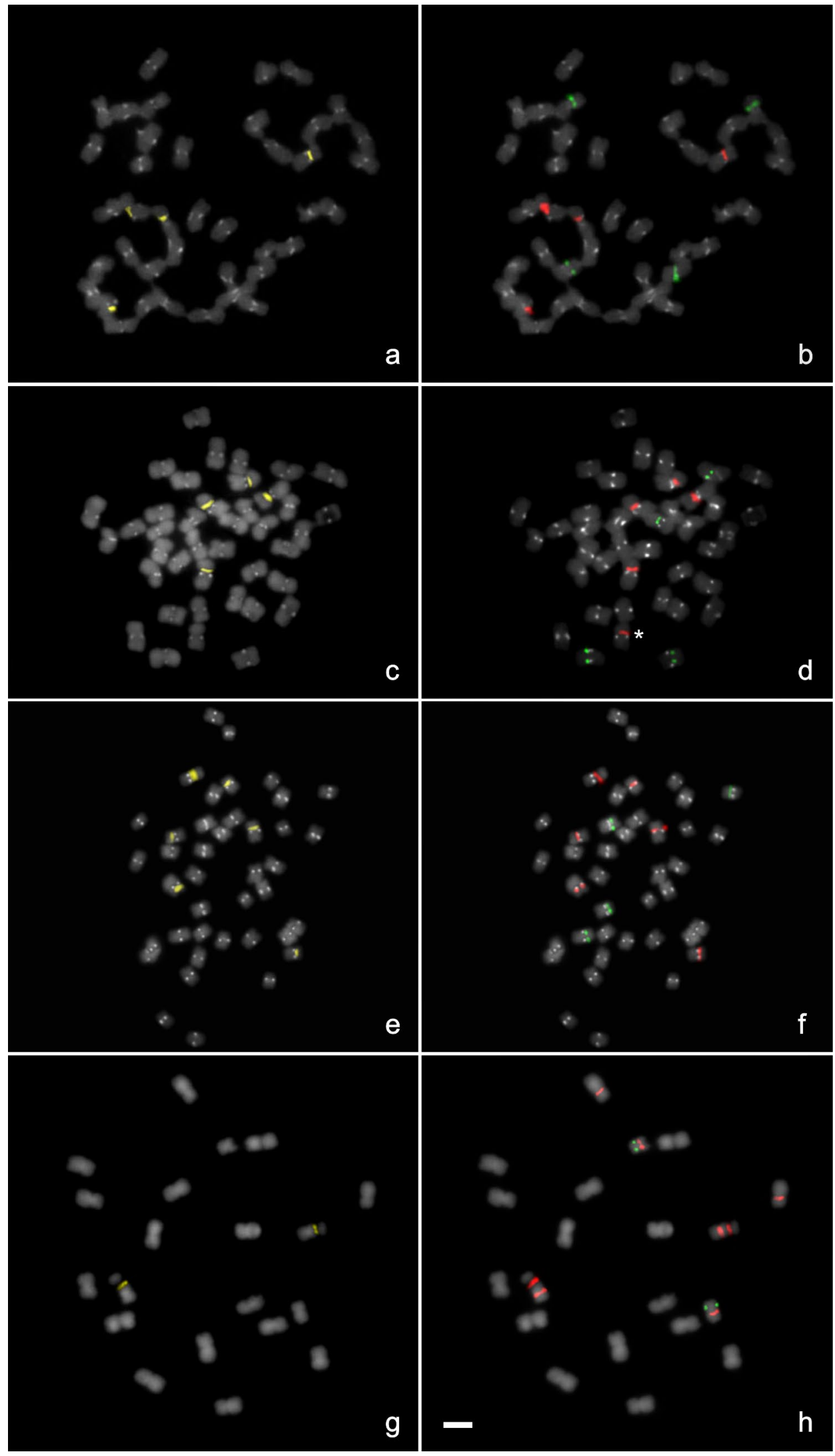


$\mathrm{K})$ and $A$. burkartii remained as independent OTUs while the other ones formed a large cluster.

Within the large cluster, the two A genome species ( $A$. duranensis and A. stenosperma) of the section Arachis grouped together because they have one A9 pair and centromeric conspicuous $\mathrm{DAPI}^{+}$heterochromatin in all the chromosomes of the complement. All the other species had centromeric dot-like $\mathrm{DAPI}^{+}$heterochromatin. Among them, three subgroups were recognized: the first included the three species of the section Procumbentes, the second the two subspecies of A. paraguariensis (sect. Erectoides), and the third all the tetraploid species of the section Rhizomatosae together with A. hermannii and A. major (sect. Erectoides).

\section{Discussion}

The establishment of species relationships through chromosomal analysis is based on the premise that closely related species may have more similar karyotypes than distantly related ones (Acosta et al. 2016; Chalup et al. 2015; Robledo et al. 2009; Robledo and Seijo 2010; Seijo et al. 2004; Silvestri et al. 2015; Weiss-Schneeweiss et al. 2008). Here, we combined DAPI/CMA banding and FISH techniques to generate useful chromosomal markers for the identification of chromosome homeologies among the three rhizomatous tetraploid species and between them and the diploid species from different sections of the genus Arachis. The first detailed karyotypes of the species of the sections Rhizomatosae, Erectoides and Procumbentes here provided allowed the genome characterization of all the Rhizomatosae species and to make inferences on the origin of the tetraploid ones.

\section{Heterochromatin distribution, rDNA loci localization and karyotype patterns}

The physical mapping of DAPI/CMA heterochromatin and $5 \mathrm{~S}$ and $18 \mathrm{~S}-26 \mathrm{~S}$ rDNA loci provided strong evidence for the existence of two different karyotype patterns within the Rhizomatosae species. The common karyotype pattern for the three tetraploid rhizomatous species can be defined by the presence of SAT chromosomes type 3 (\#10), centromeric dot-like $\mathrm{DAPI}^{+}$bands in all the chromosomes of the complement, four chromosomes (\#3) with proximal 5S rDNA sites on their long arms, and four to six chromosomes (\#2 and \#10) with proximal 18-26S rDNA sites. Although all the species presented one 18-26S rDNA site proximally localized in the four chromosomes \#10, the presence of additional sites was a useful landmark for the differentiation of the species. Indeed, A. pseudovillosa and
A. nitida could be recognized by having one or two additional sites, respectively, in chromosomes \#2.

Among the tetraploid species, the facts that A. glabrata and $A$. nitida had similar chromosome length, similar amount of $\mathrm{DAPI}^{+}$heterochromatin and the same heteromorphism in chromosomes \#9 (two $\mathrm{sm}$ and two $\mathrm{m}$ ) suggest that they are more closely related to each other than to $A$. pseudovillosa, as revealed in the cluster analysis. This is concordant with their morphological features (Krapovickas and Gregory 1994; Valls and Simpson 2005) and the genetic similarity analysis done using Random Amplified Polymorphic DNA (RAPD) markers (Valente et al. 2003).

The unique karyotype pattern of the diploid rhizomatous A. burkartii was evidenced in the cluster analysis. The karyotype of this species was different from all the other diploid Arachis species by the co-localization of one $5 \mathrm{~S}$ rDNA site with one 18-26S rDNA site on pair \#3, the colocalization of two 18-26S rDNA loci on pair \#10, and the lack of DAPI ${ }^{+}$heterochromatin bands.

Species of the sections Procumbentes and Erectoides showed similar karyotype patterns, mainly characterized by the presence of centromeric dot-like $\mathrm{DAPI}^{+}$heterochromatin in all or almost all the chromosomes of the complement. The similarity observed in the cluster analysis is consistent with the genetic similarity detected using microsatellite data (Hoshino et al. 2006), by which they clustered together. The three species of the section Procumbentes showed a karyotype pattern characterized by having DAPI ${ }^{+}$ heterochromatin in all the chromosomes of the complement, submetacentric SAT chromosomes type 9, and interstitial 18-26S rDNA sites on the short arms of pair \#10. In the species of the section Erectoides, two karyotype subgroups were recognized. One was represented by the two subspecies of A. paraguariensis, which have short chromosomes, eight pairs with DAPI ${ }^{+}$heterochromatin, proximal 18-26S rDNA sites on the long arms of pair \#10 and the chromosomes harboring the 5S rDNA sites (\#3) without $\mathrm{DAPI}^{+}$heterochromatin. The other karyotype subgroup included the species $A$. hermannii and A. major, with large chromosomes with the proximal 18-26S rDNA sites on the short arms of pair \#10 but with $\mathrm{DAPI}^{+}$heterochromatin bands in the chromosomes harboring the $5 \mathrm{~S}$ rDNA sites. The two karyotype subgroups detected in the species of the section Erectoides are supported by the morphological differences and the low genetic affinity reported between them (Krapovickas and Gregory 1994). The two subspecies of A. paraguariensis, together with A. stenophylla, are differentiated from the other species of the section Erectoides by the absence of thickened branches on the roots, and by the disposition of the flowers. Although they are more frequent at the base of the plant in A. paraguariensis and A. stenophylla, they do not form a dense cluster as in the other Erectoides species. 


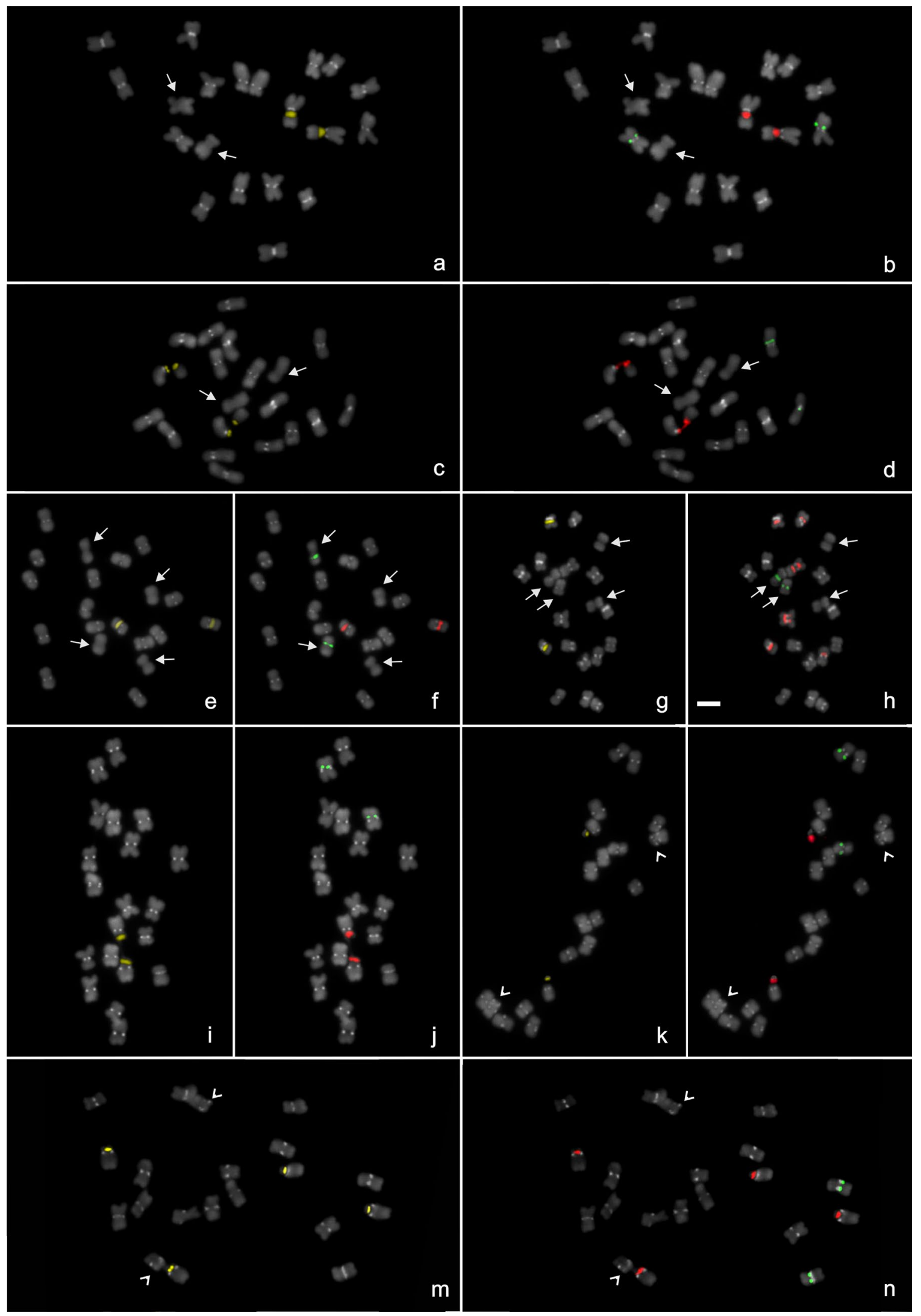


4Fig. 3 Somatic metaphases of Arachis species belonging to sections Erectoides and Procumbentes after DAPI/CMA double staining (left) and double FISH (right). Yellow signals correspond to the $\mathrm{CMA}^{+} \mathrm{DAPI}^{-} / \mathrm{C}-\mathrm{DAPI}^{-}$heterochromatin bands, gray signals to the $\mathrm{DAPI}^{+} \mathrm{CMA}^{-} / \mathrm{C}-\mathrm{DAPI}^{+}$heterochromatin bands, green signals to the 5S rDNA sites, and red signals to the 18-26S rDNA sites. Arrows indicate chromosomes without $\mathrm{DAPI}^{+}$bands and arrowhead indicates chromosomes with subtelomeric DAPI $^{+}$bands. a-h section Erectoides, $\mathbf{i}-\mathbf{n}$ section Procumbentes. a, b A. hermannii, $\mathbf{c}, \mathbf{d}$ A. major, e, $\mathbf{f}$ A. paraguariensis subsp. capibariensis, $\mathbf{g}, \mathbf{h}$ A. paraguariensis subsp. paraguariensis, $\mathbf{i}, \mathbf{j}$ A. lignosa, $\mathbf{k}, \mathbf{l}$ A. rigonii, $\mathbf{m}, \mathbf{n} A$. appressipila. Scale bar $3 \mu \mathrm{m}$

\section{Polyploidy nature of the rhizomatous tetraploids}

The heterochromatin banding and physical mapping of the $5 \mathrm{~S}$ and $18 \mathrm{~S}-26 \mathrm{~S}$ rRNA genes by FISH have been widely used to make inferences about the nature of polyploids in several plant groups (Lavia et al. 2011; Li et al. 2001; Nielen et al. 2010; Seijo et al. 2004; Souza et al. 2012; Tomas et al. 1997). Molecular cytogenetic approaches have shown that polyploid plant genomes usually undergo rapid and dynamic genomic changes upon or immediately following polyploidization (Krishnan et al. 2001; Lim et al. 2007; Piellicer et al. 2013; Weiss-Schneeweiss et al. 2007, 2008), while others appear to be the sum of their parental diploid species (Garcia et al. 2009; Pires et al. 2004; Seijo et al. 2004). Cytogenetic analyses in Arachis polyploids-A. hypogaea, A. monticola and A. pintoi-have shown that polyploidy by itself does not induce significant changes in the organization of ribosomal loci or heterochromatic bands, since their karyotypes are equivalent to the sum of those of the diploid progenitor species, regardless of whether they are autopolyploid as A. pintoi 3x (Lavia et al. 2011) or allopolyploids as $A$. monticola and A. hypogaea (Samoluk et al. 2015; Seijo et al. 2004).

Concerning the rhizomatous tetraploids analyzed here, controversial hypotheses have been put forward for the nature of $A$. glabrata. Some authors have proposed that this species is an autopolyploid but have not provided a genome formula (Singh and Simpson 1994), while others have suggested that it may be an allopolyploid with the EERR genome constitution (Bechara et al. 2010; Gregory and Gregory 1979). Although A. glabrata has an heteromorphism in chromosomes \#9 (two $s m$ and two $m$ ), the similar patterns of CMA-DAPI heterochromatin and rDNA sites observed here in the four chromosome sets are compatible with the hypothesis that considers this species as an autopolyploid. The detection of one to eight quadrivalents in the meiotic analyses of several accessions (Ortiz et al. 2011) also supports the autopolyploid nature of $A$. glabrata. Moreover, the similar patterns of the chromosome landmarks detected here in the two varieties of $A$. glabrata suggest that they may have originated from a single event of polyploidization, or if multiple, from the same diploid species.

The meiotic chromosome pairing in $20 \mathrm{II}$ in most (65\%) of the cells and the detection of configurations including up to four multivalents (trivalents and quadrivalents) in low frequencies (0.14 III and $0.45 \mathrm{IV}$ ) suggest that $A$. nitida may have two different chromosomes sets but with partial homology (Ortiz et al. 2011). The presence of one 18-26S rDNA site in only two of the four chromosomes \#2 and the different morphology among chromosomes \#9 (two $m$ and two $s m$ ) support that this species has two partially different chromosome complements. Therefore, A. nitida may be considered as a segmental allopolyploid that may have resulted from the hybridization of two species with the same pattern of $\mathrm{DAPI}^{+}$heterochromatin and the $5 \mathrm{~S}$ rDNA sites, but different number and position of the 18-26S rDNA sites and morphology of chromosomes \#9.

The overall chromosome morphology, the similar distribution pattern of CMA-DAPI bands in the four chromosome sets, and the presence of one $5 \mathrm{~S}$ and one $18-26 \mathrm{~S}$ rDNA site in the four chromosomes \#3 and \#10, respectively, suggest that A. pseudovillosa may be an autopolyploid. Under this assumption, the extra 18S-26S rDNA locus detected in only one chromosome \#2 (out of four) may have arisen de novo by transposition (or other genomic mechanism) after polyploidization. However, analysis of the meiotic behavior of A. pseudovillosa is needed to fully understand the polyploid nature of this species.

\section{Evolutionary relationships between diploid and tetraploid Rhizomatosae species}

The comparative cytogenetic analysis evidenced that the rhizomatous tetraploid species are closely related because they have a common karyotype pattern. This close relationship has also been evidenced by RAPD (Nóbile et al. 2004) and simple sequence repeat (SSR) analyses (Angelici et al. 2008). Thus, the karyotype similarity and the genetic affinity revealed by molecular markers suggest that the three tetraploids belong to a natural group and that they may have at least one common diploid ancestor.

As the section Rhizomatosae is taxonomically defined (Krapovickas and Gregory 1994), the most parsimonious hypothesis would consider $A$. burkartii as one of the diploid donors of the rhizomatous tetraploids. However, our cytogenetic analysis evidenced that the karyotype of $A$. burkartii is very different from those of the tetraploids and does not support that hypothesis. The complete reproductive isolation reported between $A$. burkartii and the tetraploids (Krapovickas and Gregory 1994) is in accordance with the cytogenetic results.

Morphologically, A. burkartii has the standard petal of the papilionaceous flower with reddish lines on both 


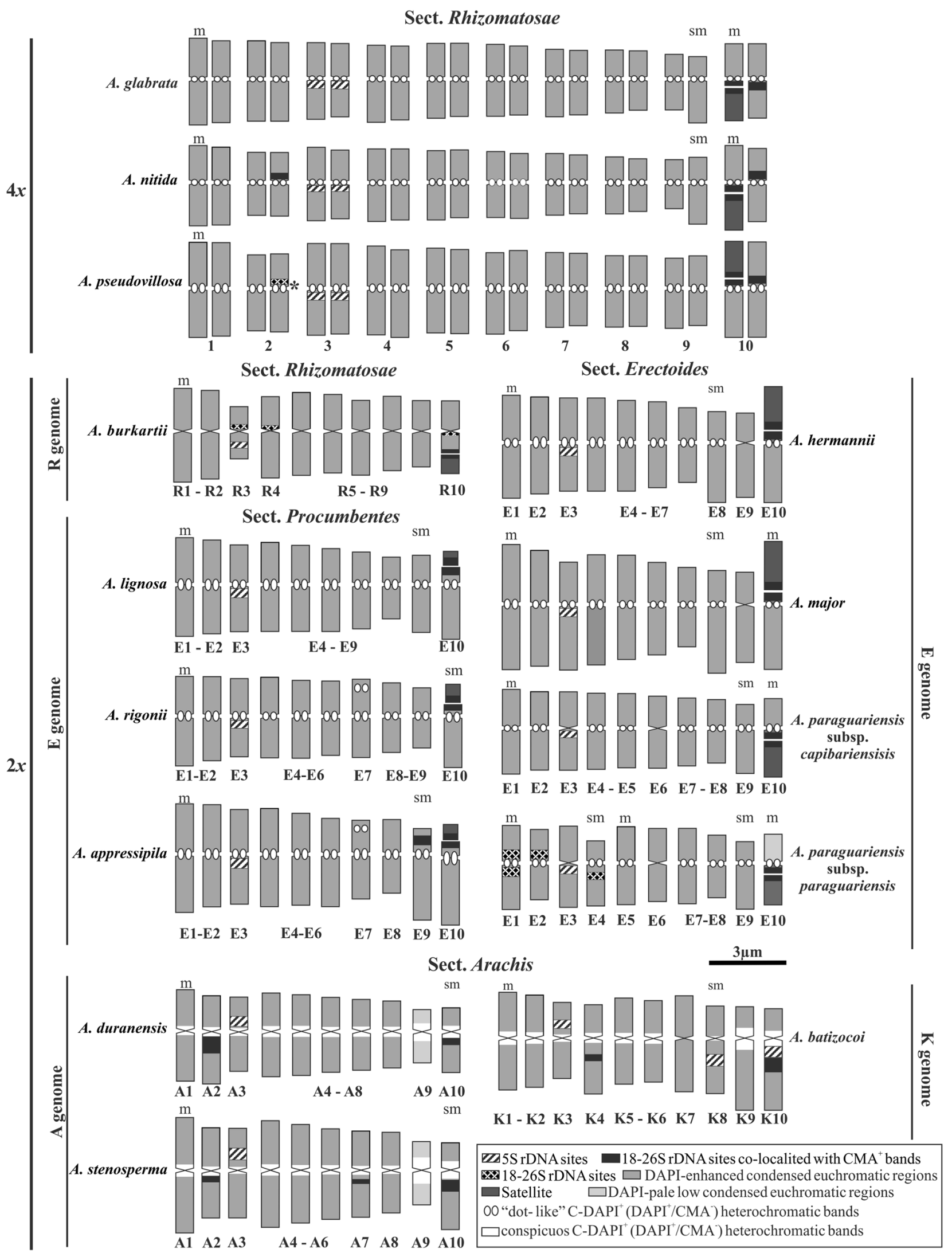


4Fig. 4 Idiograms of Arachis species belonging to sections Rhizomatosae, Erectoides and Procumbentes showing the distribution of chromosome landmarks mapped by CMA-DAPI banding and FISH. Asterisk in one pair \#2 of A. pseudovillosa indicates the 18-26S rDNA site observed in only one homologous chromosome. The chromosomes were ordered by morphology and then according to decreasing size. Some chromosomes within each idiogram were reordered according to tentative homeologies on the basis of the current nomenclature proposed for other Arachis species (Seijo et al. 2004; Robledo et al. 2009; Robledo and Seijo 2010). In the tetraploid species, the tentative homeologous chromosome pairs are represented by the same number. The idiograms of $\mathrm{A}$ and $\mathrm{K}$ genome species were redrawn from Robledo and Seijo (2010); the morphology of the satellites is not available. Scale bar $3 \mu \mathrm{m}$

surfaces and coriaceous leaflets with the margin marked on both surfaces (Krapovickas and Gregory 1994). These characters are not present in any of the rhizomatous tetraploids. Furthermore, A. burkartii grows mainly in the lower part of the Uruguay River basin, covering great part of the Rio Grande do Sul state (Brazil), the north of Uruguay, and northeast of Argentina (Krapovickas and Gregory 1994). Arachis glabrata var. glabrata grows from the south of Goiás state, west of Minas Gerais state, and northern half of São Paulo state in Brazil to the south of Paraguay and northeast of Argentina. More recently, a few populations have been found in the east of Bolivia (Seijo et al. unpublished, Herbarium CTES, Argentina). Arachis glabrata var. hagenbeckii grows in the southeast of Paraguay and northeast of Argentina, in a restricted area that overlaps the range of the variety glabrata. The other two tetraploid species, A. pseudovillosa and A. nitida, have more restricted distribution areas and grow in the Amambay and Concepción departments in Paraguay and the south of Mato Grosso do Sul state in Brazil (Krapovickas and Gregory 1994; Valls and Simpson 2005). Only A. glabrata overlaps with the diploid A. burkartii in a small area in the extreme northeast of Argentina (Fig. 1), but they grow in different environments and have never been found growing together. Thus, the morphological differences and the parapatric and allopatric distribution of $A$. burkartii with A. glabrata and A. nitidalA. pseudovillosa, respectively, support the rejection of the hypothesis that considers A. burkartii as one of the diploid progenitors of the rhizomatous tetraploids.

Molecular marker analyses including the four Rhizomatosae species, like RAPD (Nóbile et al. 2004) and SSR (Angelici et al. 2008), showed that the tetraploid species clustered together, while A. burkartii was distantly segregated in the trees. In the amplified fragment length polymorphism (AFLP) analysis, A. burkartii was associated with the two species of the section Caulorrhizae (Gimenes et al. 2002) but not with the rhizomatous tetraploids. In addition, molecular phylogenies based on ITS sequences (Bechara et al. 2010; Friend et al. 2010), which only included A. burkartii and A. glabrata, showed that $A$. burkartii is distantly related to A. glabrata. Thus, molecular markers and sequence analyses strongly support the conclusion obtained from the cytogenetic data about the relationships among the rhizomatous species.

\section{Genomic considerations in the section Rhizomatosae and genome donors of the tetraploids}

Traditionally, the Rhizomatosae species were assigned to the $\mathrm{R}$ genome based on the infrageneric divisions (Smartt and Stalker 1982). Considering the cross-compatibility reported among Rhizomatosae species (Gregory and Gregory 1979), Smartt and Stalker (1982) advanced the tentative assignation of $\mathrm{R}_{1}$ to the diploid $A$. burkartii and of $\mathrm{R}_{2}$ and $\mathrm{R}_{3}$ to the tetraploid species. However, according to the cytogenetic results provided here, the tetraploid species should be excluded from the $\mathrm{R}$ genome, which might remain exclusively for A. burkartii. The conservation of the $\mathrm{R}$ genome for $A$. burkartii is based on its strong reproductive isolation from the other species of the genus (Krapovickas and Gregory 1994), its particular chromosome characteristics (this work), and the isolated position in the phylogenetic analyses (Bechara et al. 2010; Friend et al. 2010).

With the tetraploids excluded from the $\mathrm{R}$ genome, their genome affinities were searched among those described for the other Arachis species. For this purpose, the intersectional hybrids reported among the rhizomatous tetraploids and diploid species of the genus (Krapovickas and Gregory 1994; Smartt and Stalker 1982) were considered, particularly among representatives of the $\mathrm{A}, \mathrm{K}$, and $\mathrm{E}$ genomes.

Based on crossing assays (Krapovickas and Gregory 1994) and meiotic chromosome pairing analyses of the F1 hybrids (obtained by embryo rescue) between A. glabrata and some A genome species (A. diogoi, A. duranensis and A. stenosperma), it has been suggested that one of the diploid progenitors of this tetraploid should belong to the A genome (Mallikarjuna 2004). However, the cytogenetic analysis done here evidenced that the complements of the rhizomatous tetraploids do not have the characteristic A9 pair and that the pattern of DAPI ${ }^{+}$heterochromatin bands (dot-like instead of conspicuous bands) is different from that published for the A genome species (Robledo et al. 2009; Seijo et al. 2004). Thus, although some A genome species form $\mathrm{F}_{1}$ hybrids and partially overlap their distribution areas with the tetraploids, the cytogenetic data suggest that they should be discarded as probable progenitors of the rhizomatous tetraploids.

Concerning the $\mathrm{K}$ genome species, although $\mathrm{F}_{1}$ hybrids between A. batizocoi and the three rhizomatous tetraploid species have been reported, they never or poorly flowered. The exception is one hybrid with A. nitida that has $0.03 \%$ of pollen viability (Krapovickas and Gregory 1994; Valls 


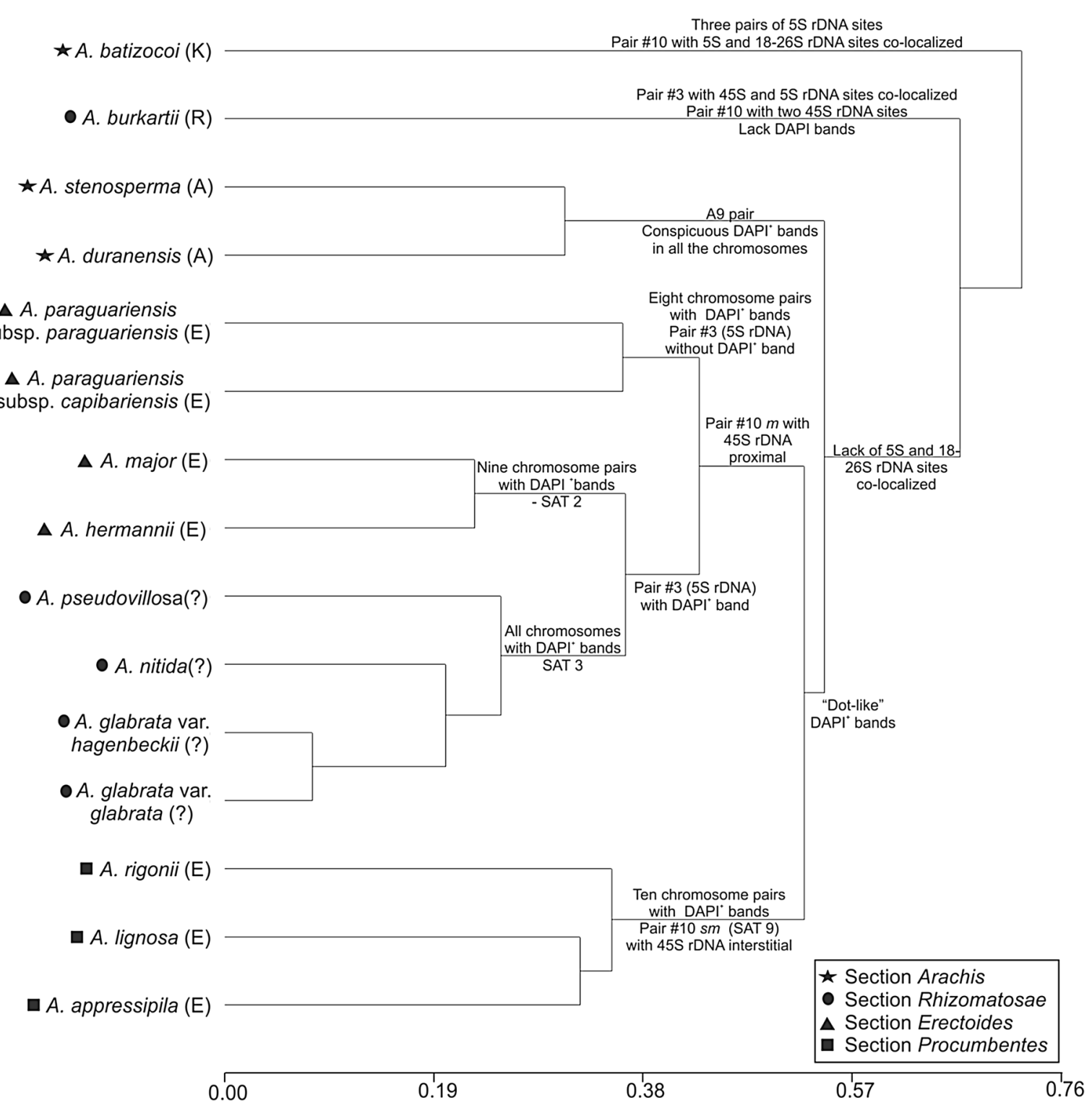

Fig. 5 Dendogram representing the relationship among the karyotypes of several Arachis species from sections Rhizomatosae, Erectoides, Procumbentes and Arachis. Letters in parentheses are the designations of genome type. $m$ metacentric, $s m$ submetacentric chro-

and Simpson 2005). Cytogenetically, A. batizocoi has a higher number of 5S rDNA and 18-26S rDNA sites, one pair of each type of rDNA sites co-localized in pair \#10 and a pattern of $\mathrm{DAPI}^{+}$heterochromatin (Robledo and Seijo 2010) different from that of the chromosome complements of the tetraploids. The $\mathrm{K}$ genome species have conspicuous $\mathrm{DAPI}^{+}$bands distributed in nine chromosome pairs of the complement (Seijo et al. 2004; Robledo and Seijo 2010). Thus, the hypothesis that A. batizocoi (K genome) is one of the genome donors of the tetraploids should also be discarded. The distribution of A. batizocoi mosomes. Clustering was performed using unweighted pair-group linkage type, with the Gower distance method and standard deviation for scaling. Cophenetic correlation coefficient $(r) 0.95$

in a distant geographical area from those of the tetraploid Rhizomatosae species supports this proposal.

Gregory and Gregory (1979) suggested that rhizomatous tetraploids consist of many poorly differentiated forms of an ancestral amphidiploid between one diploid species from Rhizomatosae and one from the E genome group. The $\mathrm{E}$ genome includes all species of the sections Procumbentes, Erectoides and Trierectoides. Rhizomatous tetraploids produce $\mathrm{F}_{1}$ hybrids with diploid species of the sections Erectoides (four species) and Procumbentes (two species) (Krapovickas and Gregory 1994; Stalker 1985; Valls and Simpson 2005). Moreover, some of these 
$\mathrm{F}_{1}$ produce normal flowers with different percentage of pollen viability, such as $A$. hermannii $\times A$. pseudovillosa (46.1\%), A. major $\times$ A. nitida (29.6\%), A. appressipila $\times$ A. glabrata $(22.2 \%)$ and A. rigonii $\times$ A. glabrata $(14.9 \%)$. This evidences that the rhizomatous tetraploids are genetically more compatible with the E genome species than with the other species of Arachis.

Our results revealed that Procumbentes and Erectoides species (karyotypes by FISH of Trierectoides species are not known yet) have centromeric dot-like $\mathrm{DAPI}^{+}$bands distributed in almost all the centromeres, one $5 \mathrm{~S}$ rDNA site localized on the long arm of a medium sized chromosome, and one 18-26S rDNA site on the SAT chromosomes in each chromosome set. This pattern is the most compatible with those observed in the rhizomatous tetraploids, although the chromosome landmarks observed in the tetraploid complements cannot be fully reconstructed from the sum of the characters of any pair of diploid species analyzed in this work.

Concerning A. glabrata, the molecular phylogenies evidence that this species is closely associated with species of the section Procumbentes (Bechara et al. 2010; Friend et al. 2010). However, the latter have SAT chromosomes type 9 (pair \#10) and a chromosome pair with subtelomeric $\mathrm{DAPI}^{+}$bands (A. rigonii and A. appressipila), which were not found in this rhizomatous tetraploid. Thus, from a cytogenetic point of view, to consider Procumbentes species as genome donors of $A$. glabrata would have required the occurrence of a paracentric inversion in the short arm of pair \#10. It is also remarkable that the Procumbentes species here analyzed are allopatric both with A. glabrata and among themselves (Fig. 1).

On the other hand, the four Erectoides species reported to produce $\mathrm{F}_{1}$ hybrids with $A$. glabrata are sympatric with this tetraploid species (Fig. 1). Among them, A. paraguariensis subsp. capibariensis, in spite of having fewer chromosomes with $\mathrm{DAPI}^{+}$heterochromatic bands, has the most similar pattern of chromosome markers expected for the genome donor of A. glabrata.

The karyotype of A. pseudovillosa has a pattern of heterochromatic bands and rDNA sites similar to that of the Erectoides species with the largest chromosomes (A. major and $A$. hermannii). The moderate pollen viability of the $\mathrm{F}_{1}$ hybrids obtained between $A$. hermannii and this tetraploid (Kraprovickas and Gregory 1994) supports the close relationships between these species. Furthermore, the distribution areas of these two diploids are close to that of A. pseudovillosa, but the area of A. major overlaps with that of this tetraploid in Amambay and Concepción departments in Paraguay and south of Mato Grosso do Sul state in Brazil (Fig. 1). These results suggest that A. hermannii, A. major or a species with a similar karyotype may be considered the most probable diploid genome donor of A. pseudovillosa.
Arachis nitida has the two types of chromosomes with the 18-26S rDNA sites observed in A. glabrata and A. pseudovillosa. This suggests a first hypothesis that A. nitida may have originated by hybridization between these two tetraploids. Besides the karyotype similarities, the three tetraploid species have overlapping distributions in Amambay and Concepción departments in Paraguay (Fig. 1). Moreover, hybrids between them have been reported, but without data on the fertility of pollen (Krapovickas and Gregory 1994).

An alternative hypothesis for the origin of A. nitida may consider hybridization between $A$. paraguariensis subsp. capibariensis and a diploid species of the section Erectoides with two metacentric chromosome pairs having rDNA sites on the short arms. However, the latter chromosomal features were not found in the diploid Erectoides species analyzed in this work. Thus, to test the latter hypothesis, a larger survey including additional Erectoides species is required for a more compressive understanding of the origin of A. nitida.

In summary, the comparative chromosome analysis presented here, supported by the reproductive and geographic isolation and the genetic differences suggests that (1) the section Rhizomatosae is a polyphyletic group constituted by two groups of species, one of them composed of the three rhizomatous tetraploid species and the other by the distant diploid A. burkartii, (2) the $\mathrm{R}$ genome of A. burkartii is not homologous to that of any of the rhizomatous tetraploids, (3) the E genome diploid species are the most closely related to the tetraploid Rhizomatosae species, and (4) rhizomes may have arisen at least twice in the genus Arachis. We envision that these data will be useful for breeders to select diploid parents in the genetic improvement of the existing A. glabrata commercial cultivars and for the development of new ones.

Acknowledgements We thank the financial support provided by the Secretaría General de Ciencia y Técnica de la Universidad Nacional del Nordeste; Consejo Nacional de Investigaciones Científicas y Técnicas and the Agencia Nacional de Promoción Científica y Tecnológica (PI 2008 No. 038, PIP No. 859, PICTO 2007 No. 099, PICTO No. 2011-0230, PICTO No. 2011-0260, PICT No. 2012 No. 1875). We also thank $\mathrm{CNPq} / \mathrm{Brazil}$ for the Research Productivity Grant (312215/2013-4) to JFM Valls. G Lavia, A Ortiz, G Robledo and $\mathrm{G}$ Seijo are research staff membres of CONICET.

\section{References}

Acosta MC, Moscone EA, Cocucci AA (2016) Using chromosomal data in the phylogenetic and molecular dating framework: karyotype evolution and diversification in Nierembergia (Solanaceae) influenced by historical changes in sea level. Plant Biol 18:514-526

Angelici CMLCD, Hoshino AA, Nóbile PM, Palmieri DA, Valls JFM, Gimenes MA, Lopes CR (2008) Genetic diversity in 
section Rhizomatosae of the genus Arachis (Fabaceae) based on microsatellite markers. Genet Mol Biol 31:79-88

Bechara MD, Moretzsohn MC, Palmieri DA, Monteiro JP, Bacci M, Martins J, Gimenes MA (2010) Phylogenetic relationships in genus Arachis based on ITS and 5.8 S rDNA sequences. BMC Plant Biol 10:255. doi:10.1186/1471-2229-10-255

Bowman AM, Wilson GPM, Gogel BJ (1998) Evaluation of perennial peanuts (Arachis spp.) as forage on the New South Wales north coast. Trop Grassl 32:252-258

Chalup L, Samoluk SS, Solís Neffa V, Seijo G (2015) Karyotype characterization and evolution in South American species of Lathyrus (Notolathyrus, Leguminosae) evidenced by heterochromatin and rDNA mapping. J Plant Res 128:893-908

Di Rienzo JA, Casanoves F, Balzarini MG, González L, Tablada M, Robledo CW (2015) InfoStat version 2015. Grupo InfoStat, FCA, Universidad Nacional de Córdoba, Argentina. http:// www.infostat.com.ar

Fernández A, Krapovickas A (1994) Cromosomas y evolución en Arachis (Leguminosae). Bonplandia 8:187-220

Friend SA, Quandt D, Tallury SP, Stalker HT, Hilu KW (2010) Species, genomes, and section relationships in the genus Arachis (Fabaceae): a molecular phylogeny. Plant Syst Evol 290:185-199

Garcia S, Garnatje T, Pellicer J, McArthur ED, Yakovlev SS, Vallés J (2009) Ribosomal DNA, heterochromatin, and correlation with genome size in diploid and polyploid North American endemic sagebrushes (Artemisia, Asteraceae). Genome 52:1012-1024

Gimenes MA, Lopes CR, Valls JFM (2002) Genetic relationships among Arachis species based on AFLP. Genet Mol Biol 25:349-353

Gregory WC, Gregory MP (1979) Exotic germplasm of Arachis L. interspecific hybrids. J Heredity 70:185-193

Gregory WC, Gregory MP, Krapovickas A, Smith BW, Yarbrough JA (1973) Structures and genetic resources of peanuts. In: Wilson CT (ed) Peanuts-culture and uses. Am Peanut Res and Educ Assoc, Stillwater, pp 47-133

Greilhuber RJ, Speta F (1976) C-banded karyotypes in the Scilla hohenackeri group, S. persica and Puschkinia (Liliaceae). Plant Syst Evol 126:149-188

Hoshino AA, Bravo JP, Angelici CM, Barbosa AVG, Lopes CR, Gimenes MA (2006) Heterologous microsatellite primer pairs informative for the whole genus Arachis. Genet. Mol Biol 29:665-675

Jahnavi MR, Murty UR (1985) A preliminary pachytene analysis of two species of Arachis L. Theor Appl Genet 70:157-165

Krapovickas A, Gregory WC (1994) Taxonomía del género Arachis (Leguminosae). Bonplandia 8:1-186

Krishnan P, Sapra VT, Soliman KM, Zipf A (2001) FISH mapping of the $5 \mathrm{~S}$ and $18 \mathrm{~S}-28 \mathrm{~S}$ rDNA loci in different species of Glycine. $\mathrm{J}$ Heredity 92:295-300

Lavia GI (2000) Chromosome studies in wild Arachis (Leguminosae). Caryologia 53:277-281

Lavia GI, Fernández A, Seijo JG (2008) Cytogenetic and molecular evidences on the evolutionary relationships among Arachis species. In: Sharma AK, Sharma A (eds) Plant genome: biodiversity and evolution, vol 1E. Science Publishers, Calcutta, pp 101-134

Lavia GI, Ortiz AM, Fernández A, Seijo JG (2011) Origin of triploid Arachis pintoi Krapov. and W.C. Gregory (Leguminosae) by autopolyploidy evidenced by FISH and meiotic behavior. Ann Bot 108:103-111

Levan A, Fredga K, Sandberg AA (1964) Nomenclature for centromeric position on chromosomes. Hereditas 52:201-220

Li R, Taylor S, Jenkins G (2001) Unravelling the phylogeny of tetraploid Vicia amoena (Fabaceae) and its diploid relatives using chromosomal landmarks. Hereditas 134:219-224
Lim KY, Matyasek R, Kovarik A, Leitch A (2007) Parental origin and genome evolution in the allopolyploid Iris versicolor. Ann Bot 100:219-224

Mallikarjuna N (2004) Meiotic study of intersectional hybrids between Arachis hypogaea, A. duranensis and A. diogoi with A. glabrata. IAN 24:7-8

Moscone EA, Matzke MA, Matzke AJM (1996) The use of combined FISH/GISH in conjunction with DAPI counterstaining to identify chromosomes containing transgene inserts in amphidiploid tobacco. Chromosoma 105:231-236

Muir JP, Butler TJ, Ocumpaugh WR, Simpson CE (2010) 'Latitude 34', a perennial peanut for cool, dry climates. J Plant Reg 4:106-108

Nielen S, Almeida LM, Carneiro VTC, Araujo ACG (2010) Physical mapping of rDNA genes corroborates allopolyploid origin in apomitic Brachiaria brizantha. Sex Plant Reprod 23:45-51

Nóbile PM, Gimenes MA, Valls JFM, Lopes CR (2004) Genetic variation within and among species of genus Arachis, section Rhizomatosae. Genet Resour Crop Evol 51:299-307

Ortiz AM, Seijo JG, Fernández A, Lavia GI (2011) Meiotic behavior and pollen viability of tetraploid Arachis glabrata and A. nitida species (Section Rhizomatosae, Leguminosae): implications concerning their polyploid nature and seed set production. Plant Syst Evol 292:73-83

Peñaloza A, Valls JFM (2005) Chromosome number and satellite chromosome morphology of eleven species of Arachis (Leguminosae). Bonplandia 14:65-72

Piellicer J, Garcia S, Valles J, Kondo Katsuhiko, Garnatje T (2013) FISH mapping of $35 \mathrm{~S}$ and $5 \mathrm{~S}$ rRNA genes in Artemisia subgenus Dracunculus (Asteraceae): changes in number of loci during polyploid evolution and their systematic implications. Bot J Linn Soc 171:655-666

Pires J, Lim CKY, Kovarík A, Sek RM, Boyd A, Leitch AR, Leitch IJ, Bennett MD, Soltis PS, Soltis DE (2004) Molecular cytogenetic analysis of recently evolved Tragopogon (Asteraceae) allopolyploids reveal a karyotype that is additive of the diploid progenitors. Am J Bot 91:1022-1035

Prine GM (1964) Forage possibilities in the genus Arachis. Soil Crop Sci Soc Fla Proc 24:187-196

Prine GM. (1972) Perennial peanuts for forage. Soil Crop Sci Soc Fla 32:33-35

Prine GM, Dunavin LS, Moore JE, Roush RD (1981) "Florigraze" rhizoma peanut: a perennial forage legume. Agr Exp Sta, Univ of Florida, Gainsville, Circular S-275

Prine GM, Dunavin LS, Gennon RJ, Roush RD (1986) “Arbrook" rhizoma peanut: a perennial forage legume. Agr Exp Sta, Univ of Florida, Gainsville, Circular S-332

Raman VS (1981) Nature of chromosome pairing in allopolyploids of Arachis and their stability. Cytologia 46:307-321

Reeves A (2001) MicroMeasure: a new computer program for the collection and analysis of cytogenetic data. Genome 44:239-443

Robledo G, Seijo G (2008) Characterization of the Arachis (Leguminosae) D genome using fluorescence in situ hybridization (FISH) chromosome markers and total genome DNA hybridization. Genet Mol Biol 31:717-724

Robledo G, Seijo G (2010) Species relationships among the wild B genome of Arachis species (section Arachis) based on FISH mapping of rDNA loci and heterochromatin detection: a new proposal for genome arrangement. Theor Appl Genet 121:1033-1046

Robledo G, Lavia GI, Seijo G (2009) Species relations among wild Arachis species with the A genome as revealed by FISH mapping of rDNA loci and heterochromatin detection. Theor Appl Genet 118:1295-1307

Robledo G, Lavia GI, Seijo JG (2010) Genome re-assignation of Arachis trinitensis (Sect. Arachis, Leguminosae) and considerations 
on its implication in the genetic origin of peanut. Genet Mol Biol 33:714-718

Romero-Zarco C (1986) A new method for estimating karyotype asymmetry. Taxon 35:526-530

Rouse RE, Roka F, Miavitz-Brown EM (2004) Guide for establishing perennial peanut as a landscape groundcover. Proc Fla State Hort Soc 117:289-290

Samoluk SS, Robledo G, Podio M, Chalup L, Ortiz JPA, Pessino SC, Seijo JG (2015) First insight into divergence, representation and chromosome distribution of reverse transcriptase fragments from L1 retrotransposons in peanut and wild relative species. Genetica 143:113-125

Santana SH, Valls JFM (2015) Arachis veigae (Fabaceae), the most dispersed wild species of the genus, and yet taxonomically overlooked. Bonplandia 24:139-150

Schweizer D (1976) Reverse fluorescent chromosome banding with Chromomycin and DAPI. Chromosoma 58:307-324

Seijo JG, Lavia GI, Fernández A, Krapovickas A, Ducasse D, Moscone EA (2004) Physical mapping of 5 S and 18-25S rRNA genes evidences that Arachis duranensis and A. ipaënsis are the wild diploid species involved in the origin of A. hypogaea (Leguminosae). Am J Bot 91:1294-1303

Seijo G, Samoluk SS, Ortiz AM, Silvestri MC, Chalup L, Robledo G, Lavia GI (2017) Cytological features of peanut genome. In: Varshney R, Pandey M, Puppala N (eds) The peanut genome, compendium of plant genomes series. Springer, Germany (in press)

Silvestri MC, Ortiz AM, Lavia GI (2015) rDNA loci and heterochromatin positions support a distinct genome type for ' $\mathrm{x}=9$ species' of section Arachis (Arachis, Leguminosae). Plant Syst Evol 301:555-562

Singh AK, Simpson CE (1994) Biosystematics and genetic resources. In: Smartt J (ed) The groundnut crop: a scientific basis for improvement. Chapman and Hall, London, pp 96-137

Smartt J, Stalker HT (1982) Speciation and cytogenetics in Arachis. In: Pattee HE, Young CT (eds) Peanut science and technology. Am Peanut Res and Educ Assoc, Yoakum, pp 21-49
Smartt J, Gregory WC, Gregory MP (1978) The genomes of Arachis hypogaea. 1. Cytogenetic studies of putative genome donors. Euphytica 27665-27675

Souza LGR, Crosa O, Speranza P, Guerra M (2012) Cytogenetic and molecular evidence suggest multiple origins and geographical parthenogenesis in Nothoscordum gracile (Alliaceae). Ann Bot 109:987-999

Stalker HT (1985) Cytotaxonomy of Arachis. In: Proceedings of International Workshop on Cytogenetics of Arachis. ICRISAT Center, Patancheru, pp 65-79

Stalker HT (1991) A new species section Arachis of peanuts with D genome. Am J Bot 78:630-637

Tomas HM, Harper JA, Meredith MR, Morgan WG, King IP (1997) Physical mapping of ribosomal DNA sites in Festuca arundinace $a$ and related species by hybridization. Genome 40:406-410

Valente SES, Gimenes MA, Valls JFM, Lopes CR (2003) Genetic variation within and among species of five sections of the genus Arachis L. (Leguminosae) using RAPDs. Genet Resour Crop Evol 50:841-848

Valls JFM, Simpson CE (2005) New species of Arachis (Leguminosae) from Brazil, Paraguay and Bolivia. Bonplandia 14:35-64

Valls JFM, Costa LC, Custodio AR (2013) A novel trifoliolate species of Arachis (Fabaceae) and further comments on the taxonomic section Trierectoides. Bonplandia 22:91-97

Weiss-Schneeweiss H, Schneeweiss GM, Stuessy TF, Mabuchi T, Park JM, Jang CG, Sun GM (2007) Chromosomal stasis in diploids contrasts with genome restructuring in auto- and allopolyploid taxa of Hepatica (Ranunculaceae). New Phytol 174:669-682

Weiss-Schneeweiss H, Tremetsberger K, Schneeweiss GM, Parker JS, Stuessy TF (2008) Karyotype diversification and evolution in diploid and polyploidy South American Hypochaeris (Asteraceae) inferred from rDNA localization and genetic fingerprint data. Ann Bot 101:909-918 